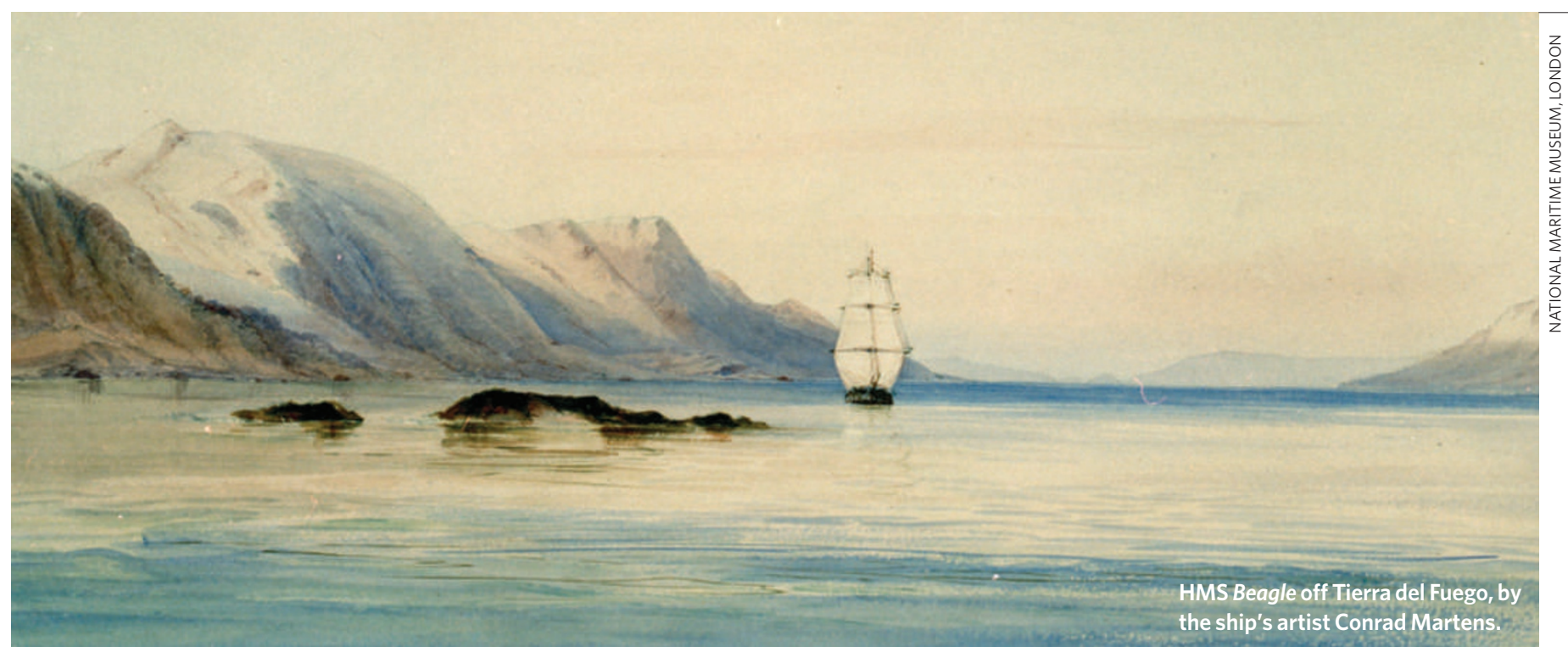

\title{
Darwin: heading to a town near you
}

\section{The theory of evolution challenges artists and philosophers as much as scientists. Joanne Baker rounds up the many forthcoming events worldwide that examine Darwin's life, his work and reactions to it.}

Charles Darwin's ideas speak to the essence of what it is to be human. Different cultures have absorbed and expressed this in different ways. His impact on science and culture is reflected in the array of exhibitions, events and books planned for 2009, in celebration of the bicentenary of his birth and the 150th anniversary of the publication of his seminal work, On the Origin of Species.

\section{Journeys}

A profound experience in Darwin's life was his five-year voyage across the southern oceans aboard the survey ship HMS Beagle. In 2009, a lucky few will be given the chance to retrace Darwin's steps. A modernized replica of the ship will carry a crew of scientists, teachers and students along the route of the 1831-36 voyage (www.thebeagleproject.com). Their experiments will be beamed to classrooms worldwide. Watching from space, astronauts aboard the International Space Station will help the crew to investigate the biology of plankton blooms, coral reefs and other oceansurface and terrestrial ecosystems.

If you have less time and US\$60,000 to spare, then you could follow Darwin's route in three weeks by private jet. Stanford University is offering this bespoke trip accompanied by three science professors, a physician and a chef. Departing from California in January, the Boeing 757 and its 92 passengers will visit the Galapagos and Easter Islands in the Pacific, Tierra
Del Fuego in South America, Tasmania, Mauritius, Cape Town in South Africa and the Cape Verde Islands off Africa's west coast. Carbon offsetting does not seem to be included.

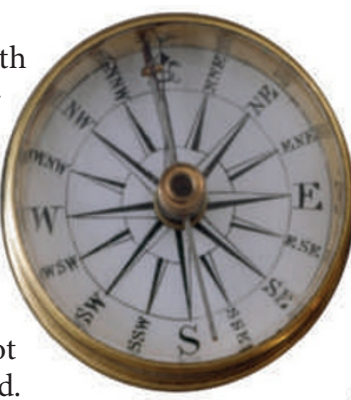

\section{Exhibitions}

Artefacts from Darwin's original voyage feature in many exhibitions, including Darwin at London's Natural History Museum, which runs until 19 April. In a week-long festival in Cambridge, UK (5-10 July; www. darwin2009.cam.ac.uk), that city's museums will display Galapagos finches (as pictured, right), barnacle microscope slides, fish, beetles, rocks and scientific instruments. Papers by Darwin and other evolutionary thinkers will be on display at the British Library, London, in Darwin and the Story of Evolution, from 10 December 2008 until 22 March.

Beyond Darwin's native United Kingdom, where most attention is understandably focused, city-wide festivals are also popular — including those in San Francisco, Philadelphia and Houston in the United States. Museums are collaborating to spread Darwin material globally. The American Natural History Museum's successful Darwin exhibition - which first went on show in New York in 2005 and has travelled across the United States, South America and Japan forms a template for some museum exhibitions, including those at London's Natural History 옫 Museum and The National Museum of Australia in Canberra, from 10 December 2008 until 29 March. The British Council is shar-

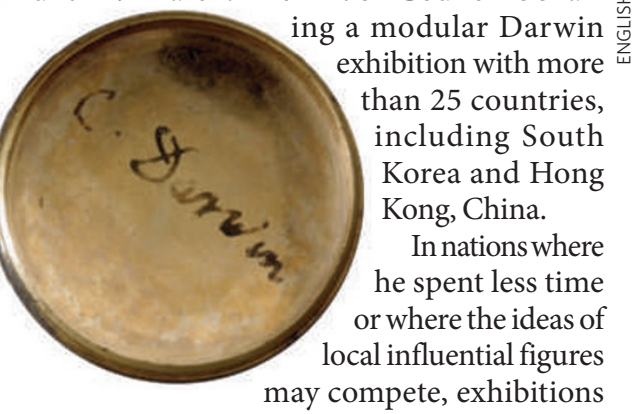
focus more on the science than the man. Darwin's Evolution at the Calouste Gulbenkian Foundation in Lisbon, Portugal, runs from 12 February until 24 May and will examine evolutionary theory from its origins to current genetics research. Other major events are planned at the Museum of Natural History (Naturkundemuseum) in Berlin, at the Toulouse Museum in France and at the State Darwin Museum in Moscow, which was founded in 1907 to cele- $\frac{\text { s }}{z}$ brate the role of Russian scientists in developing evolutionary theories. The wider social effects of Darwin's ideas will be explored at an international conference in November 2009 at the Bibliotheca Alexandrina in Alexandria, Egypt. 


\section{Imagery}

Artists' responses to Darwin's theories of human origins will be displayed at the Schirn Kunsthalle in Frankfurt, Germany. Darwin: Art and the Search for Origins (5 February until 3 May) will highlight the struggle for survival portrayed in paintings such as Passion Flowers and Hummingbirds by Martin Johnson Heade, depictions of the emergence of life by Arnold Böcklin and Odilon Redon, and Max Ernst's artistic explorations of 'deep time'. Endless Forms: Charles Darwin, Natural Science and the Visual Arts shows at the Yale Center for British Art in New Haven, Connecticut (12 February until 3 May), and then at the Fitzwilliam Museum, Cambridge, UK (16 June until 4 October). It will explore the importance of visual imagery in the development of Darwin's ideas and the effect of his theories on artists such as J. M. W. Turner, Edgar Degas, Claude Monet and Paul Cézanne.

\section{Performances}

Darwin's quest to understand human origins also motivates composers, musicians and playwrights. New music includes a cycle of folk songs and the classical Age of Wonders by British composer Michael Stimpson, which will premiere in London on 21 January before touring to Australia in September. Performances of Re:Design, a play dramatizing the correspondence between Darwin and the Harvard University botanist Asa Gray, will include a show in Cambridge, UK, on 10 July. On film, actors Paul Bettany and Jennifer Connelly will play Darwin and his wife Emma in the feature Creation, directed by Jon Amiel.

Darwin's ideas were controversial in his time, and remain so today. It is worth attending some of the many anniversary events to explore how his thinking has been interpreted, and what it says about how we see ourselves.

Joanne Baker is Nature's Books \& Arts editor.

For more on Darwin, see also pages 281 and 295, and online at www.nature.com/darwin.

For Darwin events near you, see www.darwinday. org and www.darwin200.org.

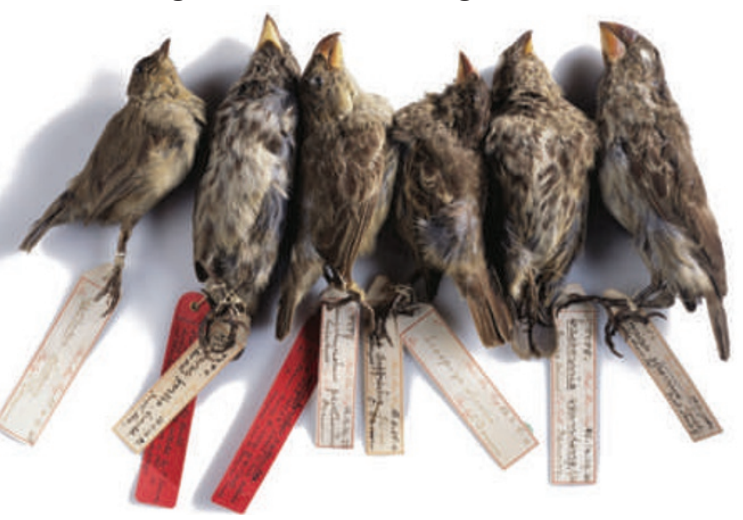

\section{A Down House bookshelf}

\section{ON THE SEAS}

Darwin's five-year voyage on HMS Beagle was spent documenting nature across the Southern Hemisphere. His full notes are now compiled in Charles Darwin's

Notebooks From the

Voyage of the Beagle by historian John van Wyhe with Gordon

Chancellor and

Kees Rookmaaker (Cambridge Univ. Press). In Charles Darwin: The Beagle Letters, edited by

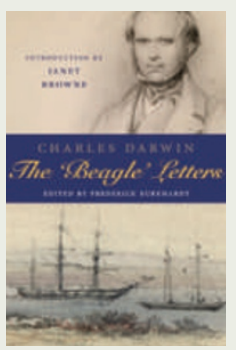

Frederick Burkhardt (Cambridge Univ.

Press), Darwin's correspondence charts his changing ideas and everyday seafaring experiences. Alan Gibbons offers young readers a cabin boy's perspective in Charles Darwin (Kingfisher). And in The Voyage of the Beagle: Darwin's Extraordinary Adventure Aboard Fitzroy's Famous Survey Ship (US Naval Institute Press), James Taylor collates the ship's plans, biographies of Darwin and Captain Robert Fitzroy, photographs, artefacts and journal extracts from the voyage.

\section{ONEVOLUTION}

In Charles Darwin: The Concise Story of an Extraordinary Man (Johns Hopkins Univ. Press), Tim Berra describes Darwin's revolutionary scientific work, its effect on modern biology and the influence of evolutionary theory on Western thought. The Rough Guide to

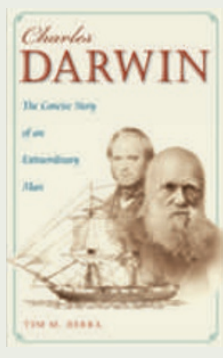

Evolution by Mark Pallen (Rough Guides) provides a popular summary, including the cultural impact of Darwin on music, plays and novels, and a list of Darwin bicentenary events.

Charles Darwin's Shorter Publications 1829-1883 by John van Wyhe (Cambridge Univ. Press) includes Darwin's theory of evolution by natural selection and more than 70 newly discovered items. The Cambridge Companion to the 'Origin of Species', edited by Michael Ruse and Robert J. Richards (Cambridge Univ. Press), draws on expert opinion to provide the religious, social, literary and philosophical contexts in which the Origin was composed.

\section{ON THE MAN}

In their controversial forthcoming biography, Darwin's Sacred Cause (Allen Lane), Adrian Desmond and James Moore will argue that Darwin's hatred of slavery fuelled

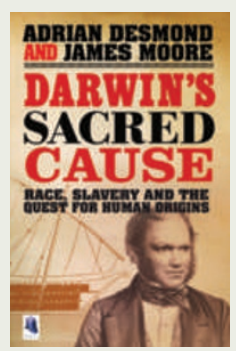
his search for a theory of human origins. After examining his manuscripts and letters, they conclude that this disgust empowered the conservative man to come up with theories that were seen as radical by his contemporaries.

Darwin's morality was also influenced by his wife's religious beliefs, according to Deborah Heiligman in her biography aimed at younger readers, Charles and Emma: The Darwins' Leap of Faith (Henry Holt). His own poor health may also have coloured his thoughts, says Ralph Colp in Darwin's Illness (Univ. Press Florida).

Or he was plain lucky, according to Patrick H. Armstrong. Darwin's Luck: Chance and Fortune in the Life and Work of Charles

Darwin (Hambledon

Continuum) asks to what extent Darwin took the wrong

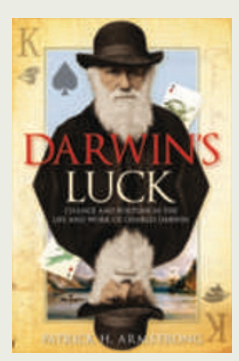
scientific paths, even if he eventually came to the right conclusions.

Darwin's exploration closer to home is the subject of Darwin's Island (Little, Brown). Biologist Steve Jones visits the British landscapes that influenced 'the sage of Kent' as much as the Galapagos Islands, and brings his work up to date. Michael Boulter's book, Darwin's Garden (Constable \& Robinson), describes

Darwin's relationship with his own garden and the experiments he carried out in his greenhouse, explains Beverley Glover in her review (see Nature 454, 944-945; 2008).

Darwin shares his birthday celebrations with Abraham Lincoln. In Angels and Ages: A Short Book About Darwin, Lincoln and Modern Life (Random House), Adam Gopnik sees both as thinkers who made and experienced great changes in society. They saw the shift away from faith and fear to the embrace of reason, argument and observation not merely as intellectual ideals, but as a way of life. 